\title{
MENGATASI JOB INSECURITY MELALUI PENDEKATAN TRANSFORMATIONAL LEADERSHIP
}

\author{
Angela Dwi Pitri ${ }^{1}$, M. Rofii ${ }^{2}$, Luky Dwiantoro $^{3}$ \\ Prodi Keperawatan Fakultas Kedokteran UNDIP Semarang ${ }^{1,2,3}$ \\ Email : angela.dp.kay@gmail.com
}

\begin{abstract}
Job insecurity is an important thing for nurses. Data says 36\% of depressed nurses are at risk 1.6 times experiencing job insecurity which results in emotional exhaustion, quit work, less productive at work, even burnout. Transformational leadership has advantages in the discipline of nursing. So that nurses need to understand the influence of transformational leadership on job insecurity. Purpose of this study is to identify the influence of transformational leadership on nurse's job insecurity. Using literature study method consisting of 24 full-text articles published by Scopus, proquest platform and science direct from 2007 to 2018 that discuss job insecurity. It was found that Job Insecurity consisted of individual Job Insecurity and Job Insecurity Climate. The transformational leadership approach can overcome job insecurity by: (1) the idealist influence of the leader demonstrates positive behavior, provides training, and demonstrates performance and commitment; (2) leader's inspirational motivation increases employee self-esteem, encourages to be productive, builds positive relationships; (3) intellectual stimulation by reducing organizational cynicism, providing tasks that are compatible with employee competencies; (3) individual consideration of the leader demonstrates good morality and ability to make decisions. It can be concluded that to overcome job insecurity, an approach with transformational leadership style can build positive behavior and establish superior and subordinate relationships.
\end{abstract}

Keywords : transformational, leadership, job insecurity

\section{PENDAHULUAN}

Beratnya beban kerja perawat membuat perawat depresi dan mengalami job insecurity. Data penelitian tahun 2018 negara cina memiliki populasi penduduk yang sangat besar. Dalam memenuhi kebutuhan pelayanan kesehatan perawat diperlukan kurang lebih sebanyak 6 juta jiwa, sementara yang teregistrasi data tahun 2014 sekitar 3 juta jiwa. Perawat harus berhadapan dengan pertambahan jumlah pasien dirumah sakit tempat bekerja. Disebabkan kekurangan tenaga perawat mereka harus bekerja ekstra dan dibawah tekanan dari kolega praktisi. Selain itu, ekspektasi publik sangat tinggi pada profesi perawat, sehingga menempatkan perawat beresiko mengalami sakit psikis karena mengalami depresi bahkan sampai bunuh diri (Zeng et al. 2018). Hasil penelitian menyebutkan 36\% 
perawat yang depresi beresiko 1,6 kali mengalami job insecurity (Yoon and Kim 2013).

Job insecurity didefinisikan sebagai keadaan tidak berdaya mengelola perasaan dalam kondisi kerja yang mengancam (Çınar, Karcıoğlu, and Aslan 2014). Job insecurity merupakan stresor penting bagi karyawan ditempat kerja (Cheng et al. 2012). Job insecurity dapat dipengaruhi oleh situasi sosial disekitar tempat kerja, yang terdiri dari dua model yaitu: persepsi personal pada job insecurity atau disebut individual job insecurity, dan persepsi personal pada iklim sekitar atau job insecurity climate (Låstad et al. 2015). Berdasarkan dua variabel diatas maka job insecurity dibagi menjadi sub-variabel diantaranya: individual job insecurity : (1) mengungkapkan tidak berdaya. Penyebab tidak berdaya adalah senioritas lebih unggul, bekerja rutinitas dan penuh dengan tekanan (Ouyang et al. 2015), rekan kerja kurang mandiri, dukungan organisasi yang kurang, kemalasan sosial (Akgunduz and Eryilmaz 2018) (2) mengungkapkan kecemasan pada keberlangsungan karir (3) mengungkapkan takut kehilangan pekerjaan dan job insecurity climate: (1) sinisme organisasi (Çınar, Karcığlu, and Aslan 2014) (2) kehilangan pemimpin yang cocok (Short 2015) (3) organisasi kurang adil (Cheng et al. 2012).

Job insecurity mengakibatkan perawat berperilaku buruk, sampai berdampak kelelahan emosi (Ouyang et al. 2015), berhenti dari pekerjaan (Akgunduz and Eryilmaz 2018), bekerja kurang produktif (Cheng et al. 2012), bahkan burnout (Çınar, Karcıoğlu, and Aslan 2014). Kenyataan ini menuntun perawat sudah harus memikirkan jaminan rasa aman bagi profesi perawat dalam bekerja. Kebutuhan saat ini bagi profesi perawat adalah seorang pemimpin. Pemimpin "adalah orang-orang yang memiliki gagasan yang jelas tentang apa yang ingin mereka capai dan mengapa" (Doyle \& Smith, 2009)(Elaine S. Marshall 2011).

Kepemimpinan transformasional memiliki keungulan model kepemimpinan yang berhasil diberbagai industri dan disiplin termasuk keperawatan (Giddens 2018). Perspektif kepemimpinan transformasional dalam keperawatan dipandang sebagai kunci sukses dengan sistem yang sudah mendunia. Kepemimpinan transformasional dipopulerkan oleh Bass pada tahun 1985, berdasarkan data yang menjadi pionir dari Burn. Gaya kepemimpinan transformasional adalah dengan cara mengumpulkan aspirasi dan motivasi karyawan, dan kemudian dengan menarik menanamkan ideal dan nilai pada kelompok. Burn mengkonsep kepemimpinan transformasinal terdiri dari empat dimensi; pengaruh idealis, inspirasi motivasi, stimulasi intelektual, dan pertimbangan individu (Schwartz et al. 2011). Dalam tulisan ini akan ditampilkan bagaimana mengatasi job insecurity perawat melalui pendekatan transformasional leadership. 


\section{METODE PENELITIAN}

Tulisan ini mengunakan pendekatan studi literatur . Dalam kesempatan kali ini akan ditampilkan bagaimana pengaruh kepemimpinan leadership terhadap job insecurity perawat. Tulisan ini didukung 24 artikel yang dipublikasikan di scopus, proquest platform dan science direct. Kriteria inklusi literatur terdiri dari artikel full-text dengan metode penelitian kuantitatif, kualitatif, dan korelasi yang dipublikasikan dari tahun 2007 sampai dengan tahun 2018, yang ditulis dengan bahasa inggris. Dengan kata kunci transformational, leadership, job insecurity.

\section{HASIL DAN DISKUSI}

Pada diagram dibawah ini menampilkan hubungan kepemimpinan transformasional dengan job insecurity.

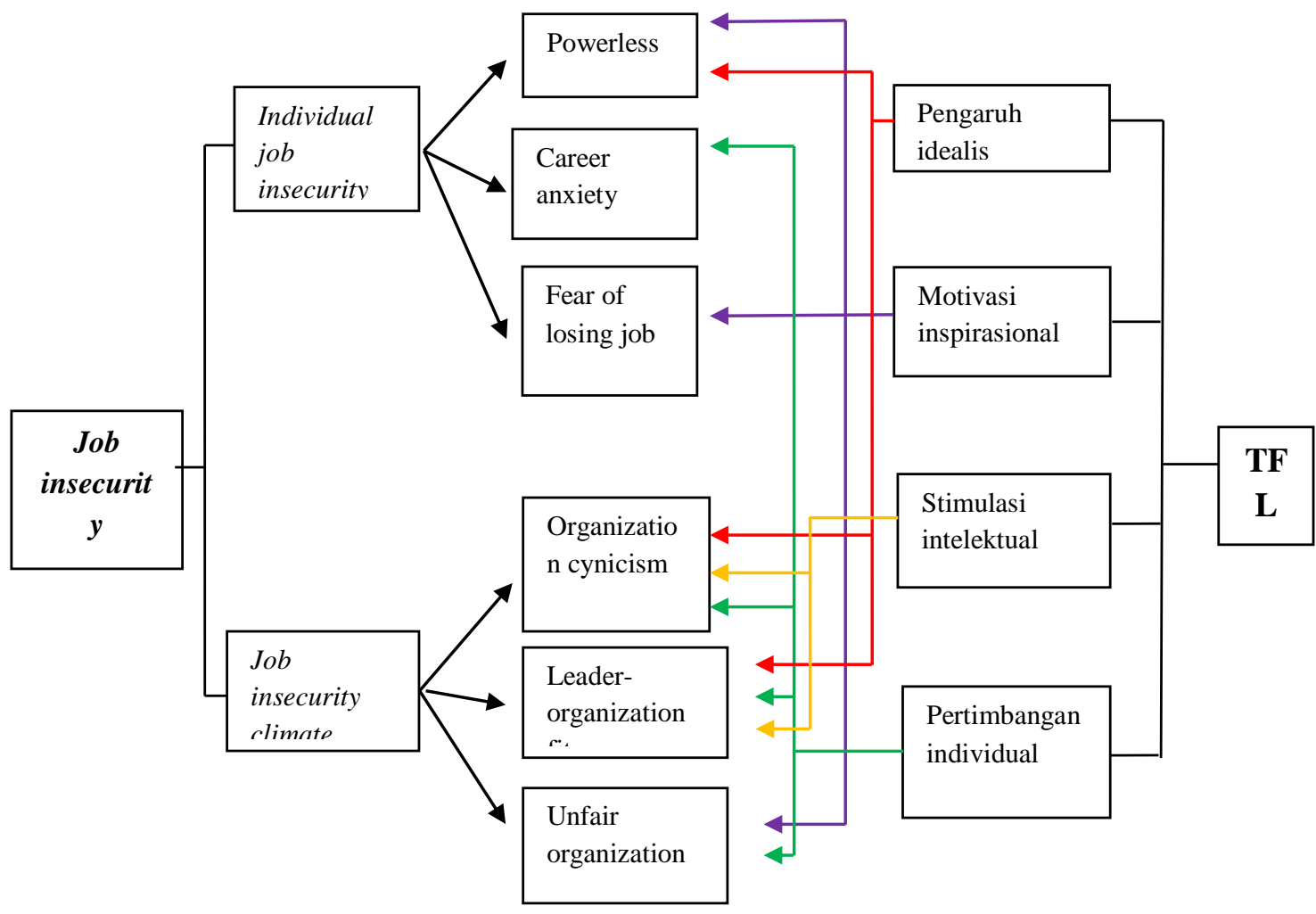

Diagram 1. Korelasi Kepemimpinan transformasional dengan job insecurity

Perilaku pemimpin melalui pendekatan kepemimpinan transformasional untuk mengatasi Job insecurity pada diagram diatas dijelaskan sebagai berikut:

\section{a. Pendekatan melalui pengaruh idealis}

Pengaruh idealis digambarkan sebagai karakter yang kuat dan melekat dalam pribadi pemimpin yang anggota kenal (Schwartz et al. 2011). 
Pendekatan pengaruh idealis dengan memberikan perhatian dan kepedulian oleh pemimpin yang dirasakan anggota dalam bentuk mentoring dan rolemodel. Pemimpin dengan model ini akan mendemonstrasikan perilaku yang membangun kepercayaan lingkungan. Keadaan ini akan membentuk penilaian perawat pada pemimpin sehingga berusaha meniru karakter pemimpin yang dianggap baik (Elaine Sorensen Marshall 2011). Pendekatan ini memberikan dorongan dari luar dan dalam diri perawat.

Pada kasus job insecurity data penelitian menunjukan bahwa pengaruh idealis: (1) mengatasi powerless melalui dukungan organisasi dengan mendemonstrasikan perilaku positif. Pendekatan ini melalui interaksi sosial dimana karyawan akan membalas respon positif pemimpin dengan meningkatkan performa dan mencapai kepuasan kerja(Astarlioglu, Kazozcu, and Varnali 2011); (2)Pengaruh idealis juga mengatasi organization cynicism dengan memberikan pelatihan dan pemberdayaan sumber daya (Y1ldiz and Şaylikay 2014). Perilaku pemimpin dapat membangun hubungan sosial dan menghilangkan keyakinan negatif; (3) Pengaruh idealis dalam mengatasi unfair organization yaitu pemimpin harus menunjukan kemampuan mengatur karyawan dengan adil dan pengambilan keputusan (Yean and Yusof 2016). Selain itu pemimpin juga mendemonstrasikan performa dan komitmen yang dapat meyakinkan karyawan sehingga terbentuk kepercayaan.

\section{b. Pendekatan melalui motivasi inspirational}

Pendekatan melalui motivasi inspirasional yaitu pemimpin akan memotivasi melalui antusiasme dan tantangan, menjelaskan visi, mendorong perubahan individu dan tim, mendukung pencapaian tujuan (Schwartz et al. 2011). Hasil penelitian menunjukan pengaruh motivasi pemimpin akan membangun motivasi intrinsik perawat. Sehingga masing-masing motivasi intrinsik akan bersatu untuk mencapai tujuan dan meningkatkan inovasi dan kreativitas dalam organisasi (Wang, Kim, and Lee 2016).

Motivasi inspirasional dapat mengatasi masalah job insecurity dengan: (1) mengatasi powerless dengan meningkatkan harga diri karyawan sehingga dapat memberikan dorongan positif dan menciptakan motivasi intrinsik karyawan (Johar 2013); (2) mengatasi Fear of losing job dapat dengan mendorong karyawan untuk meningkatkan produktifitas agar terlepas dari resiko pemecatan (Theodossiou and Vasileiou 2007); (3) Motivasi inspirasional juga mengatasi unfair organization dengan membangun hubungan positif antara atasan dan bahwahan sehingga lingkungan kerja menjadi kondusif pertumbuhan organisasi (Yean and Yusof 2016).

\section{c. Pendekatan melalui stimulasi intelektual}

Pendekatan melalui stimulasi intelektual yaitu pemimpin menantang anggota untuk dapat merubah cara pandang yang lama. Melalui inovasi, 
kreativitas dan dorongan untuk berpartisipasi dalam mengambil keputusan, dan penyelesaian masalah (An, zhang and zhan 2015). Temuan penelitian menyarankan bahwa transformational leadership akan mendorong kreativitas perawat dengan stimulasi intelektual. Melalui menantang diri akan mendorong perawat menemukan kreativitas diri melalui proses masing-masing (Çekmecelioğlu and Özbağ 2016).

Stimulasi intelektual mengatasi masalah job insecurity dengan: (1) pada kasus Organization cynicism berakibat karyawan merasa terasing, hasil penelitian menyarankan untuk memperbaiki dan dan mengurangi sinisme. Pemimpin dapat memberikan kesempatan pengembangan pengetahuan karyawan melalui pelatihan serta pemberdayaan sumber daya (Y1ldiz and Şaylıkay 2014) perilaku ini dapat menghilangkan perasaan negatif karyawan. (2) Leader-organization fit pemimpin memahami potensi atau kekuatan karyawan dan memilih tugas yang tepat sehingga karyawan merasa tertantang untuk menyelesaikan tugas dengan baik (Farooqui and Nagendra 2014). Karyawan akan merasa senang bahwa nilai-nilai yang dimiliki organisasi selaras dengan nilai mereka sendiri.

\section{d. Pendekatan melalui pertimbangan individual}

Pendekatan keempat melalui pertimbangan individual yaitu kondisi dimana anggota membutuhkan pemimpin yang memiliki keterampilan (coaching, mentoring, mendengarkan, menasehati, empati, dorongan dan umpan balik). Tugas pemimpin adalah membuat lingkungan yang mendukung untuk mencapai tujuan. Demonstrasi apresisasi dan merayakan keberhasilan sangat penting, kondisi ini membuat perawat menilai kembali usahanya, dan mengukur keberhasilan diri (Giddens 2018). Pendekatan transformasional akan meningkatkan hubungan interpersonal diantara perawat atau keterikatan kerja. Hubungan ini meningkatkan pemberdayaan sumberdaya yang memediasi efek kepuasan kerja antar perawat dan asisten medis lainnya (Giddens 2018).

Pertimbangan individual pemimpin dapat mengatasi job insecurity dengan: (1) Career anxiety dikarenakan karyawan tidak memiliki kepuasan bekerja. Sangat penting bila pemimpin memberikan dukungan agar karyawan memperlihatkan perilaku positif. Selain itu pemimpin dapat mempelajari kepribadian karyawan agar dapat membantu mengatasi rasa tidak aman dengan positif(Astarlioglu, Kazozcu, and Varnali 2011); (2) Organization cynicism sosok pemimpin yang mereka kenal akan mempengaruhi persepsi sinisme organisasi, sehingga kecocokan pemimpin sangat disarankan mengurangi sinisme dengan umpan balik moral. Artinya moral seorang pemimpin menjadi acuan perilaku karyawan; (3) Unfair organization karyawan sangat menuntut integritas dan kredibilitas pemimpin dalam kemampuan pengambilan keputusan (Yıldız and Şaylıkay 2014). Sehingga perilaku pemimpin menuruti 
nilai yang disepakati akan menciptakan kepercayaan karyawan dan mengurangi pemikiran negatif.

Pada tabel dibawah ini merupakan sintesa kepemimpinan transformasional dengan job insecurity dan menampilkan hubungannya.

Tabel .1 Telaah perilaku pemimpin untuk mengatasi job insecurity

\begin{tabular}{|c|c|c|}
\hline Variabel & Sub-variabel & Perilaku pemimpin \\
\hline \multirow{3}{*}{$\begin{array}{l}\text { Individual job } \\
\text { insecurity }\end{array}$} & Powerless & $\begin{array}{l}\text { Organisasi memberikan dukungan dengan } \\
\text { memperlihatkan perilaku positif, identifikasi } \\
\text { kepribadian yang beresiko job insecurity ketika } \\
\text { prekrutan (Astarlioglu, Kazozcu, and Varnali } \\
\text { 2011) } \\
\text { Meningkatkan harga diri karyawan dengan } \\
\text { motivasi meningkatkan kualitas kerja (Johar } \\
\text { 2013) }\end{array}$ \\
\hline & Career anxiety & $\begin{array}{l}\text { Kebijakan manager perlu memperhatikan tenaga } \\
\text { kerja, pertimbangan efek negatif dari } \\
\text { ketidaknyamanan kerja, menjamin rasa aman } \\
\text { akan meningkatkan kepuasan karyawan } \\
\text { (Astarlioglu, Kazozcu, and Varnali 2011) }\end{array}$ \\
\hline & Fear of losing job & $\begin{array}{l}\text { Pemimpin akan mendorong karyawan untuk } \\
\text { produktif untuk meningkatkan rasa aman } \\
\text { (Theodossiou and Vasileiou 2007) }\end{array}$ \\
\hline \multirow{4}{*}{$\begin{array}{l}\text { Job insecurity } \\
\text { Climate }\end{array}$} & $\begin{array}{l}\text { Organization } \\
\text { cynicism }\end{array}$ & $\begin{array}{l}\text { Mengurangi sinisme organisasi dapat } \\
\text { meningkatkan komitmen karyawan(Rubin et al. } \\
\text { 2009) } \\
\text { Sinisme organisasi membuat karyawan merasa } \\
\text { terasing mengatasi masalah dengan memberikan } \\
\text { pelatihan(Ylldı and Şaylıkay 2014) } \\
\text { mengurangi sinisme organisasi dapat } \\
\text { meningkatkan pemberdayaan sumber daya } \\
\text { (Çınar, Karcioğlu, and Aslan 2014) }\end{array}$ \\
\hline & $\begin{array}{l}\text { Leader-organization } \\
\text { fit }\end{array}$ & $\begin{array}{l}\text { Karyawan lebih stress bila pemimpin pasif dan } \\
\text { menghindar dari permasalahan(Baysak and } \\
\text { Yener 2015) }\end{array}$ \\
\hline & & $\begin{array}{l}\text { Pemimpin memiliki kewajiban moral } \\
\text { menciptakan kecocokan dari tuntutan keinginan } \\
\text { karyawan yang ahirnya akan menguntungkan } \\
\text { institusi (Fisher and Wilmoth 2018) } \\
\text { Kecocokan pemimpin diungkapkan sebagai } \\
\text { pemberian tugas sesuai dengan kompetensinya } \\
\text { (Farooqui and Nagendra 2014) }\end{array}$ \\
\hline & Unfear organization & $\begin{array}{l}\text { Organisasi memberikan dukungan positif dan } \\
\text { adil dalam pengambilan keputusan (Yean and } \\
\text { Yusof 2016) }\end{array}$ \\
\hline
\end{tabular}

Perilaku kepemimpinan transformasional untuk mengatasi job insecurity berdasarkan hasil penelitian dan menjelaskan dampaknya tertera pada ditabel 1 . 


\section{KESIMPULAN}

Job insecurity adalah ketidakmampuan perawat mengelola perasaan ketika berhadapan dengan tekanan kerja dan situasi mengancam. Data penelitian menunjukan ada dua model job insecurity yaitu individual job insecurity meliputi pengalaman mengungkapkan perasaan tidak berdaya, mengungkapkan kecemasan dan takut kehilangan pekerjaan sedangkan job insecurity climate yaitu pengalaman sinisme organisasi, kehilangan pemimpin yang cocok, dan organisasi kurang adil. Permasalahan job insecurity dapat diselesaikan melalui pendekatan transformational leadership yaitu pengaruh idealis, inspirasi motivasi, stimulasi intelektual, dan pertimbangan individu. Tulisan ini merekomendasikan kepada pemimpin keperawatan untuk mengatasi job insecurity melalui pendekatan transformational leadership.

\section{DAFTAR PUSTAKA}

Akgunduz, Yilmaz, and Gamze Eryilmaz. 2018. "Does Turnover Intention Mediate the Effects of Job Insecurity and Co-Worker Support on Social Loafing?" International Journal of Hospitality Management 68(March 2017): 41-49.

AN, Li-yan, Li ZHANG, and Shao-bin ZHAN. 2015. "The Impact of Transformational Leadership on Nurse Psychological." International Conference on Management Science \& Engineering 2(2): 71-76.

Astarlioglu, Melih, Secil Bayraktar Kazozcu, and Renin Varnali. 2011. "A Qualitative Study of Coping Strategies in the Context of Job Insecurity." Procedia - Social and Behavioral Sciences 24: 421-34.

Baysak, Birol, and Müjdelen İ. Yener. 2015. "The Relationship Between Perceived Leadership Style and Perceived Stress on Hospital Employees." Procedia Social and Behavioral Sciences 207: 79-89. http://linkinghub.elsevier.com/retrieve/pii/S1877042815052921.

Çekmecelioğlu, Hülya Gündüz, and Gönül Kaya Özbağ. 2016. "Leadership and Creativity: The Impact of Transformational Leadership on Individual Creativity." Procedia - Social and Behavioral Sciences 235(October): 24349. http://linkinghub.elsevier.com/retrieve/pii/S1877042816315543.

Cheng, Ting, Guo-hua Huang, Cynthia Lee, and Xiaopeng Ren. 2012. "Longitudinal Effects of Job Insecurity on Employee Outcomes: The Moderating Role of Emotional Intelligence and the Leader-Member 
Exchange." Asia Pacific Journal of Management 29(3): 709-28. http://link.springer.com/10.1007/s10490-010-9227-3.

Çınar, Orhan, Fatih Karcıoğlu, and İmran Aslan. 2014. "The Relationships among Organizational Cynicism, Job Insecurity and Turnover Intention: A Survey Study in Erzurum/Turkey." Procedia - Social and Behavioral Sciences 150: 429-37. http://linkinghub.elsevier.com/retrieve/pii/S1877042814050940.

Farooqui, Ms. Safia, and Asha Nagendra. 2014. "The Impact of Person Organization Fit on Job Satisfaction and Performance of the Employees." Procedia Economics and Finance 11(14): 122-29. http://linkinghub.elsevier.com/retrieve/pii/S2212567114001828.

Fisher, Elaine M., and Margaret C. Wilmoth. 2018. "Do I Take the Job?: Assessing Fit with the Organization." Journal of Professional Nursing 34(2): 82-86. https://doi.org/10.1016/j.profnurs.2017.08.003.

Giddens, Jean. 2018. "Transformational Leadership: What Every Nursing Dean Should Know." Journal of Professional Nursing 34(2): 117-21. https://doi.org/10.1016/j.profnurs.2017.10.004.

Johar, Siti Sarawati Hj. 2013. "Dimension of Neuroticism Personality among Leader and the Impact towards Self-Esteem of Employee at the Workplace." Procedia - Social and Behavioral Sciences 91: 588-93. http://linkinghub.elsevier.com/retrieve/pii/S1877042813025895.

Låstad, Lena et al. 2015. "Measuring Quantitative and Qualitative Aspects of the Job Insecurity Climate: Scale Validation." Career Development International 20(3): 202-17.

Marshall, Elaine S. 2011. Transformational Leadership in Nursing : From Expert Clinician to Influential Leader. Springer Pub. Co. http://library1.ga/_ads/7C304A9981646B72E2843233AB1155B4 (August $31,2018)$.

Marshall, Elaine Sorensen. 2011. Transformational Leadership in Nursing: From Expert Clinician to Influential Leader.

Ouyang, Zhongming, Jinyan Sang, Ping Li, and Jiaxi Peng. 2015. "Organizational Justice and Job Insecurity as Mediators of the Effect of Emotional Intelligence 
on Job Satisfaction: A Study from China." Personality and Individual Differences 76: 147-52. http://dx.doi.org/10.1016/j.paid.2014.12.004.

Rubin, Robert S., Erich C. Dierdorff, William H. Bommer, and Timothy T. Baldwin. 2009. "Do Leaders Reap What They Sow? Leader and Employee Outcomes of Leader Organizational Cynicism about Change." Leadership Quarterly 20(5): 680-88. http://dx.doi.org/10.1016/j.leaqua.2009.06.002.

Schwartz, Diane Brady, Tammy Spencer, Brigitte Wilson, and Kim Wood. 2011. "Transformational Leadership: Implications for Nursing Leaders in Facilities Seeking Magnet Designation.” AORN Journal 93(6): 737-48.

Short, Jennifer L. 2015. "LEADER-ORGANIZATION FIT AS A PREDICTOR OF JOB SATISFACTION, WORK COMMITMENT, AND JOB INSECURITY by Jennifer L . Short DANA SHELTON, PhD, Faculty Mentor and Chair BRUCE GILLIES , PhD , Committee Member BRIANNA EITER , PhD , Committee Member Andrea Mill.” (May).

Theodossiou, I., and E. Vasileiou. 2007. "Making the Risk of Job Loss a Way of Life: Does It Affect Job Satisfaction?” Research in Economics 61(2): 71-83.

Wang, Xiao Hua, Tae Yeol Kim, and Deog Ro Lee. 2016. "Cognitive Diversity and Team Creativity: Effects of Team Intrinsic Motivation and Transformational Leadership." Journal of Business Research 69(9): 3231-39. http://dx.doi.org/10.1016/j.jbusres.2016.02.026.

Yean, Tan Fee, and Ab Aziz Yusof. 2016. "Organizational Justice: A Conceptual Discussion." Procedia - Social and Behavioral Sciences 219: 798-803. http://linkinghub.elsevier.com/retrieve/pii/S1877042816301483.

Y1ldı, Sebahattin, and Mahmut Şaylıkay. 2014. "The Effect of Organisational Cynicism on Alienation." Procedia - Social and Behavioral Sciences 109(2): 622-27. http://linkinghub.elsevier.com/retrieve/pii/S1877042813051562.

Yoon, Saunjoo L, and Jeong-hee Kim. 2013. “Job-Related Stress, Emotional Labor , and Depressive Symptoms Among Korean Nurses.” : 169-76.

Zeng, Hong Jun et al. 2018. "Chinese Nurses Are at High Risk for Suicide: A Review of Nurses Suicide in China 2007-2016." Archives of Psychiatric Nursing (February): 0-1. https://doi.org/10.1016/j.apnu.2018.07.005. 